\title{
La narrativa para niños en España y Portugal entre los años 80 y 90 del siglo XX: una visión de conjunto
}

\author{
Moisés SELFA SASTRE \\ Universitat de Lleida \\ Departamento de Didácticas Específicas \\ Facultad de Ciencias de la Educación \\ mselfa@didesp.udl.cat \\ Sara Raquel Duarte REIS DA SILVA \\ Instituto da Educação \\ Departamento de Estudos Integrados de Literacia, Didáctica e Supervisão \\ Universidade do Minho \\ sara_silva@ie.uminho.pt
}

Recibido: marzo 2014

Aceptado: julio 2014

\section{RESUMEN}

Este artículo analiza el panorama de la literatura narrativa infantil publicada en España y Portugal en la década de los años 80 y 90 . Con el fin de la dictadura política en estos dos países, se abre un nuevo periodo literario en el que autores de este momento histórico escriben para un tipo de público, el infantil, que muestra curiosidad e interés por nuevas temáticas que contribuirán a su progresiva formación intelectual y lectora. Los autores, títulos y editoriales presentados en este trabajo son un fiel reflejo de la nueva literatura infantil del momento que se hace eco de estas necesidades pedagógicas.

Palabras clave: literatura infantil, narrativa, España, Portugal, fin de la dictadura.

Children's Narrative in Spain and Portugal between the 80s and 90s:

An Overview

\begin{abstract}
This essay analyzes narrative children's literature published in Spain and Portugal in the late $80 \mathrm{~s}$ and $90 \mathrm{~s}$. With the end of political dictatorship in these countries, it occurs a new literary period in which authors of this historic moment write to a sort of public, children, who shows curiosity and interest in new topics that will help his progressive intellectual and reading formation. The authors, titles and publishers presented in this study are a reflection of the new children's literature of that time, making echo of these educational needs.
\end{abstract}

Keywords: Children's literature, narrative, Spain, Portugal, end of dictatorship. 


\section{Le récits pour enfants en Espagne et Portugal des années 80 à 90 du XX siècle: une vue d'ensemble}

\section{RÉSUMÉ}

Cet article analyse le panorama de la littérature infantile pour les enfants, publiée en Espagne et en Portugal durant la décade des années 80 et 90 . Á la fin de la dictadure politique dans ces deux pays, a lieu une nouvelle période littéraire pendant laquelle des auteurs de ce moment historique écrivent pour une sorte de public, infantile, qui démontre avoir cusiosité e intérêt pour des nouvelles tématiques qui contribuiront a leur progressive formation intelectuelle et lectrice. Les auteurs, les titres et les éditions présentés dans ce travail devienent un fidéle reflet de la nouvelle littérature pour les enfants du moment que se fait écho de ces besoins pédogogiques.

Mots-clé: la littérature pour enfants, narrative, Espagne, Portugal, fin de la dictadure.

SUMARIO: 1. La narrativa infantil en la década de los 80 a los 90 en España y Portugal: algunas consideraciones. 2. La literatura narrativa infantil (años 80-90) en España: autores, editoriales, temas y categorías de lectores. 3. La literatura narrativa infantil (años 80-90) en Portugal: autores, editoriales, temas y categorías de lectores. 4. Conclusiones. 5. Bibliografía.

\section{LA NARRATIVA INFANTIL EN LA DÉCADA DE LOS 80 A LOS 90 EN ESPAÑA Y PORTUGAL: ALGUNAS CONSIDERACIONES}

A mediados de la segunda mitad de los años 70, España (1975) y Portugal (1974) asisten a un momento histórico que supone el fin de la dictadura en estos dos países. Progresivamente, y a partir sobre todo de los 80 , se consolida un nuevo periodo democrático que supondrá la creciente apertura ${ }^{1}$ de ambos países a diversas tendencias culturales que quedarán plasmadas en ámbitos de conocimiento y expresión como es el de la literatura infantil (García Padrino, 1992; BravoVillasante 1985, 285-304).

${ }^{1}$ En efecto, en el caso concreto del contexto cultural portugués, cabe señalar que los mecanismos represivos del Estado Nuevo y del período salazarista integraban un rígido sistema de censura en todo aquello que se publicaba en la prensa y que se extendió progresivamente a otros medios de comunicación como el teatro, el cine, la radio y la televisión. Nada podía ser publicado, editado o difundido sin previa autorización de los censores. Este mecanismo tuvo efectos perjudiciales en la producción literaria de los escritores portugueses, cuya creatividad se vió así truncada. Obras de autores canónicos como Aquilino Ribeiro, Soeiro Pereira Gomes o José Régio fueron incluso confiscadas. Además, la literatura para niños publicada durante el régimen dictatorial salazarista fue objeto de una regulación estatal explícita con la publicación oficial por la Dirección General de los Servicios de Censura, en 1950, de las Instrucciones para la Literatura Infantil de cuya aplicación se ocupó una Comisión Especial para la Literatura Infantil y Juvenil (Gomes, Ramos y Silva, 2009). 
Como sabemos, la literatura infantil, como la escrita para adultos, es un reflejo de las vicisitudes de tipo histórico, cultural y social que afectan directamente a la comunidad en la que esta literatura vive. Frecuentemente, estas vicisitudes ejercen su influencia en los activos pedagógicos, entre los cuales ocupa un lugar preferente y prioritario la escuela, que reclama un tipo de libro, en este caso infantil, que se ocupe del proceso de aculturación del niño y de la formación de las estructuras de conocimiento que este debe adquirir como parte de una generación en periodo de construcción de su propia identidad (Colomer, 1998, 81; Gómez del Manzano, 1997).

Por otra parte, es a partir de los años 80 del siglo XX cuando el niño, que ocupa un papel activo de persona que lee y por tanto conoce, tiene acceso a una producción literaria más variada y diversa que le permite escoger entre un conjunto de diferentes lecturas. Estas van desde los clásicos de los siglos anteriores al XX hasta las tendencias literarias más actuales que se abren camino en un panorama literario caracterizado, principalmente, por una gran diversidad de autores, títulos y temas literarios.

Entre los factores que favorecen el desarrollo de una nueva literatura infantil en España y Portugal a partir de los años 80 y 90, moderna y en consonancia con la sociedad en la cual esta literatura vive, podemos hablar de los siguientes:

1. Aumenta de un modo extraordinario el número de autores e ilustradores que conciben su obra para el público infantil. El autor de literatura infantil deja de sentirse un autor de segunda fila y pasa a adoptar un papel activo como constructor de un nuevo conocimiento válido y funcional para el niño (Colomer, 1992). Paralelamente, los ilustradores abren sus puertas de creación a las nuevas corrientes que proceden del mundo del arte y reivindican su papel de recreadores del texto y no como simples ornamentadores de este. Es el caso, por ejemplo, del escritor e ilustrador español Arcadio Lobato, autor de álbumes ilustrados como El mayor tesoro (1988), cuya obra fue reconocida internacionalmente en la Bienal de Bratislava en 1983 y con el Premio Europeo de Álbum ilustrado de 1991. En Portugal, por su parte, podemos referirnos a las figuras de Maria Keil, ilustradora de libros de la colección Histórias de Amor de Mais - Os Presentes (1979) y As Três Maçãs (1988), de Leonor Praça y Tucha y Bicó (1969/1977), y de Manuela Bacelar y su trabajo de ilustración en los volúmenes de la colección Tobias, $O$ Dinossauro (1990) y $O \mathrm{Meu} A v \hat{o}$ (1990), por exemplo. La obra de esta artista fue, en 1989, reconocida internacionalmente con la Manzana de Oro de la Bienal de Ilustración de Bratislava gracias a las ilustraciones del texto Silka (1984/1990), de Ilse Losa. De hecho, como señalábamos detalladamente en otro lugar (Silva, 2011), estos trabajos inauguran la publicación en Portugal de los denominados álbumes narrativos para las primeras edades (picture story books) escritos e ilustrados por una misma autora.

2. Aparece una multitud de premios creados por instituciones públicas y privadas que estimulan y promocionan la producción literaria para el público 
infantil. Un ejemplo de este tipo de premios es el Premio Nacional de Literatura Infantil y Juvenil que es uno de los Premios Nacionales de Literatura que se convoca en España desde 1978 y otorga el Ministerio de Cultura. En el caso portugués, aunque no podamos señalar la existencia de un premio nacional, cabe destacar, por su importancia y reconocimiento, el Premio Calouste Gulbenkian de Literatura para Niños instituido desde $1980^{2}$ y vigente a día de hoy. Paralelamente, después de 1974, son varios los premios que, en Portugal, son organizados por entidades municipales (como el Premio Maria Rosa Colaço, instituido por el Ayuntamiento de Almada), por editoriales (como los de la Editorial Verbo y del Caminho), por la Asociación Portuguesa de Escritores (que, en 1978, instituye el Premio de Literatura para Niños) y organismos estatales como la Secretaría de Estado del Medio Ambiente o la Secretaría de Estado de la Cultura que instituyeron el Premio de Teatro Infantil (en colaboración con la sección portuguesa del IBBY) así como el Premio Nacional de Ilustración (desde 1996).

3. Emergen nuevas tendencias pedagógicas que reivindican su papel en el derecho a la educación pluralista y no ideológica del niño (Lage Fernández, 1996, 43-50). Se fomenta la creatividad y el derecho a la imaginación de este y se arrinconan progresivamente las intenciones moralizantes y sexistas que hasta el momento tomaban una única dirección en la formación de las generaciones de niños que ya habían iniciado su paso por la primera escuela de los años 40 y que se prolongó hasta mediados de los 70 (Colomer, 1991, 14-24). En Portugal, por ejemplo, el movimiento pedagógico conocido como Educación por el Arte, que preconiza la acción, el ludismo, la creatividad, la expresión autónoma y espontánea, el autodesarrollo y la relación afectiva o emocional, gana seguidores que, además, y en algunos casos, tienen también un importante papel en el campo de la literatura para niños como es el caso de Alice Gomes.

4. En el campo editorial, los avances técnicos permiten la impresión de libros muy atractivos en los que empieza a predominar el colorido de las ilustraciones (Wensell 1999, 151-163) y de otros aspectos gráficos, como la diversidad de formatos de páginas, a unos precios que tienen la clara voluntad de ser asequibles. Paralelamente, las relaciones comerciales entre países son cada vez más fluidas, sobre todo a partir de la celebración de la Feria del Libro en Bolonia en el año 1963, acontecimiento que se repite año tras año y que supone el punto de encuentro entre el público lector y las nuevas tendencias literarias y editoriales que van abriéndose paso en el mercado progresivamente. En Portugal, el trabajo de algunas editoriales creadas en la última década de los 70 facilita que la literatura e ilustración para niños se consolide con la publicación de títulos significativos. Citemos, a título de ejemplo, la editorial portuguesa Plátano y las colecciones publicadas en esta como Lagarto Pintado (coordinada por uno de los autores más

${ }^{2}$ Roig, Soto y Neira, 2013. 
notables de la literatura para niños del momento, António Torrado) y Caracol; Sá da Costa Infantil y la colección Ler e Reler (Serie Cisne Branco); Livros Horizonte que apostó por colecciones como Histórias por Imagens, Sete Estrelas y Pássaro Livre; y la colección Uma Aventura de la Editorial Caminho. En el caso de estas dos últimas editoriales, cabe señalar que su oferta editorial continúa vigente a día de hoy con una notable vitalidad.

5. A todo ello, hay que añadir las progresivas transformaciones sociales cuyas consecuencias tienen que ver con el interés real por la escolarización e instrucción de toda la población, especialmente la infantil incluso en zonas rurales y poco industrializadas. Se regula, en España, el acceso al inicio de la vida laboral del joven y se prohíbe el trabajo infantil. Además, las nuevas formas de vida que predominan exigen un nivel mínimo de formación en lectura y comprensión de textos para poder acceder a un lugar de trabajo desde el cual poder participar en un nuevo tipo de vida moderna que se gesta con la instauración de la democracia. En Portugal, por su parte, se asiste a la implementación, ampliación y consolidación de la red de educación preescolar, es decir, de los jardines de infancia destinados a niños de 3 a 6 años. Se inaugura también las tele-escuelas que apuestan por la enseñanza a distancia y que posibilitan el acceso a esta a niños de las zonas más recónditas y rurales del país. La escolaridad obligatoria se alargó con la aprobación de la Ley de Bases del Sistema Educativo en 1986 y los índices de analfabetismo fueron decreciendo progresivamente.

6. Por último, queremos destacar el hito que supuso la creación de bibliotecas populares y gratuitas por parte de la Administración (Valriu 1994, 126-127). Sin la consolidación de este espacio pedagógico, luminoso y de acceso libre, no puede entenderse la formación y difusión de la literatura infantil en los años 80 y 90. Su función será la de impulsar actividades que fomenten la lectura como medio de entretenimiento y de conocimiento. Dos de los primeros precedentes de este tipo de bibliotecas los encontramos en París hacia 1924 con la creación de L'heure joyeuse y en Munich con la Internationale Jugendbibliothek inaugurada en 1949. En el caso portugués, más allá de las importantes bibliotecas fijas e itinerantes de la Fundación Calouste Gulbenkian, se asiste a la inauguración de varias decenas de bibliotecas en muchas sedes de municipios, implementándose así una importante Red Nacional de Bibliotecas de Lectura Pública. A estas se añadieron otro tipo de bibliotecas particularmente importante en la promoción de la lectura en el contexto escolar: las Bibliotecas Escolares con interesantes colecciones y con un trabajo debidamente organizado en esta Red.

En todo este entramado de vicisitudes histórico-culturales se inscribe la literatura narrativa infantil de entre los años 80 y 90 en España y Portugal. Se trata de una literatura con unos autores que cultivan un determinado tipo de temas y que publican para un lector bien determinado. Desde este punto de vista, tanto en España como en Portugal, como en Europa, podemos hablar de unas tendencias comunes y generales que, como es sabido, proceden y en algunos casos se inician 
en los anteriores años 70 y que terminan por consolidarse en la década que va entre los años 80 y 90 (Vásquez, 2003, 69-73): la narrativa infantil realista (Albanell 1990, 25-29; Gasol \& Lissón 1989, 20-27), la literatura narrativa infantil fantástica y la literatura narrativa infantil realista fantástica (Vásquez, 2003, 69-73).

La narrativa infantil realista es aquella que cuenta una historia que podía haber pasado y que queda enmarcada en un contexto que entendemos como posible o real. Se trata de obras con un claro tono idealista que narran aspectos de la vida cotidiana y en las que sus personajes son normalmente niños inocentes que se limitan a cumplir las normas establecidas por personajes que poseen una cierta autoridad moral y que se prestan al diálogo. Se trata de obras como, por ejemplo, El amigo oculto y los espíritus de la tarde (1984), de C. López Narváez, que narra las vivencias del protagonista, un niño de nombre Miguel, que vive en medio rural de montaña y que conoce lo complicado que resulta poner una teja, alzar una tapia, ayudar a parir a una burra o salvar una cosecha de una riada inopinada.

Junto a este tipo de obras de tipo idealista, aparecen otras también de tipo realista pero con un claro tono crítico (Strausfeld, 1989, 83-87). Su objetivo no es otro que el de presentar al niño la realidad tal cual es. Se narran y exponen sin tapujos la problemática social y personal del momento. Su objetivo no es otro que el de intentar que se tome conciencia de la nueva realidad tras un periodo largo de dictadura. Además, suelen aparecer temas relacionados con el tránsito de la niñez a la adolescencia, las intensas relaciones interpersonales, el mundo del paro laboral y el amor. Los mercaderes del diablo (1989), de J. Farias, por ejemplo, es una obra en el que aparece la crítica a una sociedad injusta que a punto de estuvo de acabar con la vida de un niño abandonado entre los escombros de la basura.

En segundo lugar, podemos hablar de otra corriente en la literatura narrativa infantil de los años 80 y 90 que apuesta por la revitalización de la fantasía y, en concreto, por la recreación de los cuentos populares en los que aparecen trastocados los personajes tradicionales de estos: príncipes inseguros, princesas alocadas y decididas, lobos y dragones cuyo objetivo es conseguir la amistad de los humanos y, en general, un conjunto de personajes nada estereotipados que viven y se mueven en lugares también poco convencionales: ciudades, rascacielos $\mathrm{y}$, en general, ambientes muy urbanos. Se trata de un tipo de narraciones, como hemos dicho, fantásticas pero a menudo con un claro mensaje de denuncia del mundo que los rodea. Podemos mencionar, como un ejemplo de esta tendencia narrativa, El maestro y el robot (1983), de J. A. del Cañizo, narración en la que la escuela de un pueblo vago y holgazán parece que va a ser dirigida por un personaje tecnológico, un robot, que además controlará la desidia de todo el pueblo, si bien don Herminio, el buen maestro del pueblo, y su esposa van a evitar con su actuación que así sea.

En tercer lugar, podemos hablar de la literatura narrativa infantil realista fantástica, concepto que parece contradictorio pero que está relacionado con una clara intención de combinar en una misma narración personajes, lugares y tiempos 
reales con personajes, lugares y tiempos reales fantásticos. Lo que realmente destaca este tipo de literatura infantil es que la relación que se establece entre estos elementos narrativos es muy directa a pesar de que el lector deba realizar un constante ejercicio de interpretación y relación entre la realidad y la fantasía. Un ejemplo de este tipo de literatura es La gripe de Búffalo Bill (1981), de F. Climent, en el que el personaje principal es un niño que hace lo imposible por conocer a su ídolo Búffalo Bill.

\section{LA LITERATURA NARRATIVA INFANTIL (AÑOS 80-90) EN ESPAÑA: AUTORES, EDITORIALES, TEMAS Y CATEGORÍAS DE LECTORES}

España es un país del que a partir de los años 70, pero sobre todo en los 80 , va desapareciendo progresivamente el analfabetismo de los años de la inmediata posguerra (Viñao, 1989, 10). Este avance sociocultural es posible, entre otros factores, gracias a la oferta de libros para niños y jóvenes que consumirán también los adultos. La literatura infantil y juvenil podemos decir que está de moda: nacen nuevas editoriales que publican libros infantiles y juveniles, las que ya existían potencian este tipo de publicaciones y las editoriales de libros adultos crean nuevos espacios en los que el libro infantil y juvenil tiene una gran cabida y aceptación (Vásquez 2003, 77). Además, podemos hablar de una apertura hacia las tendencias literarias que están en pleno auge en Europa, con lo que se editan y traducen importantes autores como G. Rodari (Italia, 1920-1981), M. Gripe (Suecia, 1923), R. Dahl (Gales, 1916-1990), C. Nöstlinger (Austria, 1936), M. Ende (Alemania, 1924-1995), M. Sendak (Estados Unidos, 1928-2012). Los libros de estos autores tienen gran acogida por parte del público infantil y juvenil ya que ofrecen a los españoles la posibilidad de conocer la literatura infantil mundial más representativa del momento (Vásquez 2003, 68). Podemos decir, por tanto, que en los años 80 asistimos al tan comentado boom de la literatura infantil española, una explosión creativa y editorial que es paralela al resto de naciones europeas. Un dato asombroso es que hacia 1987 se editaron más de 35.000 libros de literatura infantil en España (Bravo-Villasante 1985, 285-289).

Si repasamos qué editoriales comienzan a publicar literatura infantil a fines de los 70 y principios de los 80 (Bravo-Villasante 1985, 290-300), hablaremos, en primer lugar, de Alfaguara que en el año 1977 empieza a publicar obras para el público más infantil, normalmente traducciones de autores extranjeros. También es notoria la actividad de la Editorial Miñón que en 1980 lanza la colección Las Campanas, en formato de bolsillo, en la que tienen cabida autores extranjeros pero también españoles. La Editorial SM presenta en 1980 la colección El Barco de Vapor con más de 25 títulos de autores de fama mundial entre los que encontramos también españoles. Es el caso de C. Armijo, autora de El Pampinoplas, premio El Barco de Vapor de 1979.

Las grandes editoriales, como Espasa-Calpe, crean un departamento de publicaciones infantiles. Así es como nace en 1981 la Colección Austral Juvenil en 
la que vuelven a tener cabida autores extranjeros, como L. Bojunga Nunes y su obra El bolso amarillo, Premio Andersen en 1982, y españoles como J. M. Gisbert y El misterio de la isla de Tökland (1980), ganadora del premio Lazarillo de 1981. Por su parte, la Editorial Planeta impulsa en 1981 la Colección Infantil y la Colección Juvenil donde aparecen básicamente obras de autores infantiles europeos.

La Editorial Altea presenta en 1981 su nueva colección Altea Benjamín en la que edita títulos como Soy un niño (1986) de J. L. García Sánchez. Por su parte, La Galera, en su colección La Gaviota, inicia en 1980 la publicación de libros de aventuras en la que tiene cabida autores como J. Vallvedú y Vacaciones reloj (1987) y M. del Amo y Zuecos y naranjas (1987), línea editorial que también potenciará la Editorial Debate que, en la serie Biblioteca de la Aventura, da cabida a autores extranjeros como J. Verne y sus narraciones en dos volúmenes sobre el Capitán Hatteras (1987). Paralelamente, editoriales de adultos, como Alianza Editorial, introducen en España traducciones de clásicos como los cuentos de los hermanos Grimm (1985).

Mención especial merece la editorial SM que lleva a cabo una profunda renovación de su línea editorial para el público infantil al conceder enorme importancia a un tipo de libro para pequeños en los que la imagen comienza a predominar sobre el texto. Son los conocidos álbumes narrativos infantiles para los que están aprendiendo a leer. Citemos, como ejemplos, El Caballo Fantástico (1985) de M. Ruano, Premio Lazarillo de Ilustración 1984, y El mayor tesoro (1983) de A. Lobato, Premio Europeo de Álbum Ilustrado de 1991.

En todo este entramado editorial, un buen número de autores españoles, como veremos, publican textos narrativos dirigidos al público infantil que, sin duda, siente un gran interés por la nueva literatura que está en consonancia con las corrientes literarias europeas de años 80 y 90 . Se trata de unas obras con una temática muy definida en las que predomina el libro de aventuras y las narraciones fantásticas que no impiden que se sigan editando libros infantiles con un claro tinte de realismo social (Martínez 1989, 85-89).

Entre la nómina de estos autores españoles para jóvenes lectores, podemos destacar, en primer lugar, los que escriben narraciones para aquel público infantil que está aprendiendo a leer y empieza a entrar en contacto con un tipo de texto en el que predominan pequeños relatos donde el realismo deja paso a la fantasía. Nos estamos refiriendo a autores como F. Almena y El cuchipando (1985), obra en la que un anciano inventor, don Nicanor, crea una especie de telescopio en forma de embudo que sirve para conocer cómo son las personas. También es el caso de la conocida escritora madrileña M. del Amo (1927) que publica Cuento para bailar (1982), en la que el personaje principal luchará contra la injusticia de un robo en plena sabana y querrá convertirse en el jefe de su tribu viviendo así un conjunto de aventuras un tanto fantásticas, y Tranquilino (1990), narración ambientada en un país imaginario pero de apariencia real en el que un joven rey, Traquilino, 
emprende la tarea de rescatar a su padre, con la ayuda de unas ardillas, que está prisionero de otro monarca. Mil años más tarde, otro niño empleará la espada de Traquilino para rasgar una muralla de humo que había dejado sin sol la ciudad.

P. Mateos es otra de las autoras que en esta década publica narraciones para lectores principiantes en las que realismo y fantasía van de la mano. Uno de sus títulos significativos es Capitanes de Plástico, premio Lazarillo de 1982, obra en la que Ernesto vive un conjunto de aventuras en una cabaña habitada por extraños y animados muñecos de plástico. Por su parte, Jorge y el capitán (1988), de A. Gómez Cerdá, nos presenta a un niño llamado Jorge que vive un conjunto de peripecias en un autobús escolar que es tragado por un monstruo y atrapado por una nube. Gracias a un personaje fantástico como es el capitán, todas estas aventuras tendrán siempre un final feliz.

Si bien el realismo fantástico es una línea temática para estos jóvenes lectores tal como hemos visto, sin duda alguna el tipo de narraciones que más se escribirán para este tipo de público inicial son aquellas en las que el realismo y la inocencia de sus personajes destacan por encima de cualquier otro elemento textual. Es el caso, por ejemplo, de títulos como El boquete (1985), de J. Ballaz, en las que dos niños viven una intensa amistad en medio de un largo y tedioso verano; La paloma, el cuervo y otros cuentos (1987) y Dudú y Pepe (1983), de C. Kurtz, narraciones cuentísticas protagonizadas por animales; Memorias de una gallina (1989) de C. López Narváez que relata la vida de la gallina Carolina desde su infancia hasta su vida adulta en el gallinero de la granja en la que vive; Macaco y Antón (1986), de A. Gómez Cerdá, narración en la que destaca la inocencia de dos protagonistas infantiles que han hecho realidad el sueño que tenían de convertirse en maquinistas de un tren de mercancías; y Mi tío Teo (1987), de P. Mateos, relato infantil en la que una niña de diez años espera la visita de su tío Teo, más pequeño que ella, pero sumamente divertido y con el que podrá vivir con él y su amiga Sonia muchas aventuras.

El lector mediano infantil, que ya empieza a consolidar unas buenas estrategias de lectura y comprensión de textos literarios, es también el destinatario de las narraciones que van publicándose en las décadas que son objeto de nuestro estudio. Como se trata de un tipo de público ligeramente más maduro que el lector inicial, se publican obras en las que la fantasía cobra un gran protagonismo. Son los casos, por ejemplo, de títulos como Sopaboba (1984), de F. Alonso Alonso, narración en la que don Manuel y su alumno Juanito consiguen resolver sus problemas gracias a a una misteriosa receta culinaria en forma de sopa; La casa pintada (1990) de M. del Amo, seleccionada por la Fundación Germán Sánchez Ruipérez como una de las cien mejores obras de la literatura infantil española del siglo XX y Premio CCEI para libros infantiles y juveniles (Comisión Católica Española de la Infancia (CCEI) en 1991, en la que el niño Chao trata de conquistar los colores para vivir en una casa como la del emperador Huang-Tui; Un conejo en el sombrero (1991), de J. Ballaz, que narra el largo viaje de un payaso y su amigo Joe a una isla en busca 
de la fantasia; El Castillo de las Tres Murallas (1981), de C. Martín Gaite, obra muy corta pero intensa por las diferentes maneras que tienen sus protagonistas de buscar la libertad a partir de los sueños; La isla menguante (1987), de P. Mateos, que es la historia de una familia que vivía en una isla menguante y cuyos protagonistas viven un conjunto de aventuras disparatadas; y El pastel del diablo (1985) de esta misma autora, en la que el lector queda inmerso en unos mundos inimaginables a partir de las vivencias de una heroína a la que le picó el gusanillo de la curiosidad desde que su padre la bautizó con el nombre de Sorpresa.

El realismo fantástico también es, como para el joven lector, una línea temática que acaba imponiéndose en la narrativa para lectores medianos. Se trata de un tipo de narraciones en las que la realidad es el punto de partida para conocer e imaginar cómo puede ser un mundo totalmente nuevo y fantástico. Algunos ejemplos destacados de este tipo de narrativa infantil son los siguientes: ;Piiiiiii! (1990), de C. Armijo, que narra el viaje de un niño Javier en un tren con su perro por muchos pueblos y ciudades el día de su cumpleaños; Coco-loco. Poco-loco (1985), de G. Fuertes, que es la historia de un niño que estaba un poco loco pero que su inteligencia y curiosidad le lleva a conocer al hombre más viejo del mundo; Historias de ninguno (Premio El Barco de Vapor de 1981), de P. Mateos, en la que el niño de nombre Ninguno descubre que todo lo que pinta con una vieja caja de colores se hace realidad; y El saltamontes verde (1986), de A. M. Matute, que dibuja la figura de un niño de nombre Yugo que pierde un día misteriosamente su voz.

Pero sin duda, la narrativa de corte realista continúa, como para los lectores principiantes, publicándose para un público lector mediano a buen ritmo que es difícil abarcar todos los títulos significativos que se publican entre los años 80 y 90. A modo ilustrativo podemos hablar de las siguientes publicaciones y autores: Un solo clarinete (1987) (Premio El Barco de Vapor de 1983), de F. Almena, narra las vacaciones de verano de un niño llamado Ramón en el pueblo de sus abuelos y en donde se embarcará en una multitud de peripecias como torear una vaca lechera; Los mochuelos (1983) de C. Kurtz, que nos introduce en el particular universo de un grupo de amigos que se verán obligados a decir adiós a su cándida infancia para convertirse en adultos; El árbol de los pájaros sin vuelo (1987), de C. López Nárvaez, que es el relato de la adolescencia de una joven llamada Inés y de su amigo el pequeño vagabundo Rafaardilla con el que recorre el monte a escondidas de sus padres; Un puñado de miedos (1989) de esta misma autora, cuento de aventuras en torno a la visita que recibe el protagonista de esta narración, Quique, por parte de su tía Isabel; Jeruso quiere ser un gente (Premio El Barco de Vapor de 1981), de P. Mateos, que describe la falsedad de las primeras impresiones que tiene un niño, Jeruso, que sufre un robo al llevar el pedido de la compra al domicilio de sus clientes; y Las palabras mágicas (1983), de A. Gómez Cerdá, que nos presenta al niño Ramón y a su madre Margarita que solventarán sus diferencias aprendiendo a escucharse los dos mucho más. 
El lector autónomo, es decir, aquel que va abandonando su niñez para ser ese adolescente que requerirá un tipo de narraciones de trama complicada y personajes y escenarios de diversa tipología, es también el destinatario de buena parte de la narrativa infantil que se publicará entre los 80 y los 90 . Un buen ejemplo de este tipo de publicaciones es El bosque de piedra (1985), de F. Alonso Alonso, que nos presenta a un niño de diez años, Dito, que vive en la buhardilla de una casa humilde y al que le encanta mirar las estatuas que adornan la catedral y otros rincones de la ciudad. Las conoce tan bien a todas que ha llegado incluso a convertirse en su amigo y a crear en torno a ellas un universo personal: su bosque de piedra. Un día empieza a contarles a sus compañeros de clase historias inspiradas en este bosque, entre ellas la del Viejo Guerrero que tras plantar césped y flores decide olvidarse de las batallas y la de la penúltima hoja del otoño cuya protagonista es una hoja de parra que se le ha caído a una estatua de un parque. Por su parte, M. del Amo publica El nudo (1980), Premio Nacional de Literatura Infantil y Juvenil de 1978. El nudo son tres historias. La primera es la de una antigua tribu que vive en las montañas y que prevé el ataque invasor del enemigo del llano, infinitamente más preparado que ellos para la guerra. Solo cuentan con rústicas lanzas, arcos y flechas para defenderse. Los protagonistas, desde sus respectivos puestos de vigilancia, se comunican haciendo sonar las cuerdas de sus arcos. Esta rudimentaria forma de comunicación tendrá un efecto mágico en el ejército enemigo. La tercera historia ocurre siglos después y narra la ascensión a la cumbre de esa misma montaña de tres jóvenes y el encuentro con un ser que desfallece en el glaciar. Y la segunda es el nudo y está por escribir. Las páginas centrales del libro están en blanco para que cada cual las rellene física o mentalmente con su propio nudo. Se trata de un nudo que ata el pasado con el futuro, el misterio y la ciencia con el cielo y la tierra.

Mercedes e Inés o cuando la tierra da vueltas al revés (1981), de C. Armijo, es otro título representativo de este tipo de narrativa fantástica para un lector más autónomo. Los dos protagonistas de esta narración, Merces e Inés, están decididas a emprender un viaje pero sin llegar tarde a la clase de francés a la que debe asistir Inés. Sin pensarlo más, se suben a un bonito coche rojo con una maleta llena de garbanzos mágicos y viajarán por Rafatalu, Las Chimbambas y una playa donde se bañan con impermeable y bufanda. Gracias a los garbanzos mágicos, Inés llegará a tiempo a clase de francés. Citaremos también de esta misma autora Los machafatos (1987), narración que nos presenta a unos personajes totalmente fantásticos que pueden tener cuerpo de caballo, alas de pájaro, pueden convertirse en un tren y marchar por la vía y lo que más les gusta, aparte de los helados de coco, es caminar.

Junto a la fantasía, el realismo fantástico también es una tendencia temática presente en las narraciones para el niño lector autónomo de los años 80 y 90 . Entre las obras y autores que publican para este tipo de lectores, podemos destacar $E l$ misterio de la isla de Tökland (1981), de J. M. Gisbert, premio Lazarillo en 1980, 
una narración situada en un espacio posible, la isla de Tökland, centro de reunión de aventureros, descifradores de enigmas, científicos, periodistas, astrólogos y detectives de todo el mundo, en el que muchos son los que intentan descifrar el mayor y difícil enigma múltiple de todos los tiempos, pero sólo uno logrará acercarse al final del laberinto de la isla. Otro título que es un buen exponente del realismo fantástico es Historia asombrosas (1989), del catalán J. Sierra i Fabra, obra que nos presenta la historia de un niño atrapado en un ascensor junto a un anciano que para calmarlo le cuenta historias fantásticas. Cuando el niño sale del ascensor, no queda ni rastro del anciano. En Apareció en mi ventana (1990), A. Gómez Cerdá narra la historia de un niño, Gil, que habla y se comunica con un mukusuluba, un extraño pájaro que come papel y madera y que, además, es insaciable. Esto ocasiona innumerables problemas a Gil ya que ha decido no contarle nada a su familia. Por último, citaremos Sombrerete y Fosfatina (1990), del autor madrileño C. Puerto, que recrea la historia de estos dos imaginarios personajes en Estambul después de una desafortunada aventura a bordo de un barco.

Una tercera línea temática que los autores para un público lector autónomo infantil continúan cultivando son las narraciones de corte realistas que describen situaciones posibles y/o creíbles. Citemos como ejemplo Una casa a la deriva (1983), de J. Ballaz, en la que el abuelo de Nacho decide construirse una vivienda en medio de un lago para aislarse de las murmuraciones de sus vecinos. Querido Tim (1983), de C. Kurtz, es otra de las narraciones que podemos inscribir dentro de las narraciones de tipo realista: un gato de nombre Tim vive un conjunto de aventuras con sus diversos dueños que le cambiarán su nombre según las preferencias de estos. En Jinetes en caballo de palo (1982), Premio Narrativo Ideas por la paz de 1986, M. Osorio nos presenta la candidez e inocencia de unos niños que, a lomos de caballos de palo, proclaman su rechazo a la guerra y la necesidad de paz. Por último, en El mar sigue esperando (1983 y Premio Nacional de Literatura Infantil y Juvenil de 1982), de C. Murciano, asistimos a una narración llena de recuerdos y nostalgia: Néstor, hijo un de pescador, vive en un pequeño pueblo costero, pero tiene que reiniciar su vida en la ciudad después de la muerte de su padre y la enfermedad de su madre. La nostalgia del mar va a protagonizar sus horas de cada día. La fotografía de una playa, el rumor de una caracola, los peces en movimiento del aquarium o los inmóviles de un libro ilustrado mantendrán vivo su recuerdo. Al regresar al pueblo Néstor recuperará cuanto fue y será suyo: la barca de su padre, la ternura materna y su mar oleante, manso, intacto. 


\section{LA LITERATURA NARRATIVA INFANTIL (AÑOS 80-90) EN PORTUGAL: AUTORES, EDITORIALES, TEMAS Y CATEGORÍAS DE LECTORES}

En Portugal, después de largos años de opresión creativa bajo el poder dictatorial de António de Oliveira Salazar, un periodo que termina con la Revolución de Abril de 1974 y en la que, como señalábamos en otro artículo (Silva, 2008), dominó la edición de títulos encuadrados en los modelos estéticos y socioculturales del régimen y por la transmisión de temáticas nacionalistas y/o valores como Dios, Patria y Familia, las décadas de los 80 y 90 del siglo XX fueron años de cambio respecto al modelo anterior en lo que a literatura infantil se refiere.

Como ya mencionamos más arriba, en las dos décadas que son objeto de nuestro estudio se apuesta por la escolaridad a partir de una temprana edad de 3 años. Este hecho repercute en el aumento del número de lectores potenciales y en la producción de un tipo de literatura infantil para y destinada a los más jóvenes. Además, el interés creciente por este tipo de literatura para niños fue objeto de notas críticas y recensiones en algunos periódicos y revistas de la época.

Una variedad de autores y de ilustradores, algunos de ellos con obra ya publicada antes del fin de la dictadura salazarista, destacan en este periodo. Nos estamos refiriendo a nombres como, por ejemplo, Matilde Rosa Araújo, Luísa Dacosta, Ilse Losa, Sophia de Mello Breyner Andresen, Luísa Ducla Soares, Maria Alberta Menéres o António Torrado, solamente por citar algunos que, en algunos casos, mantienen una vitalidad creativa en la actualidad que hace que sus obras integren las listas del Plan Nacional de Lectura portugués y su lectura sea recomendada en el documento de las Metas Curriculares de Português para o Ensino Básico.

Además, se multiplican las colecciones y series de libros que nutren los fondos de las bibliotecas escolares portuguesas. Es el caso, por ejemplo, de títulos publicados en Plátano, editorial que apuesta por colecciones de obras de tamaño reducido, formato cuadrangular, tapa blanda y a un precio bastante accesible. La serie Lagarto Pintado, dirigida por Antonio Torrado, y cuya publicación se inicia en la última década de los años 70 del siglo XX, es uno de los casos de mayor éxito para los prelectores y lectores iniciales. Comprende alrededor de diez títulos detalladamente ilustrados y compuestos por textos que difunden el rico patrimonio tradicional oral, por ejemplo narraciones populares como Lá Vem a Nau Catrineta o Donzela que Vai à Guerra.

Con un grafismo muy similar a la colección Lagarto Pintado e igualmente adecuados para prelectores y lectores iniciales, los libros de la colección Sete Estrelas, que la editorial Livros Horizonte inaugura en 1983 con dos títulos de Leonor Santa-Rita y con ilustraciones de Ana Leão - Bolas de Sabão y A Semana , engloban más de veinte obras de autores cuyo universo literario tiene al niño como destinatario extratextual preferencial: Luísa Ducla Soares, Carlos Pinhão, Leonel Neves o António Torrado son algunos nombres destacados. Cabe señalar 
que muchos de ellos fueron reeditados años más tarde en volúmenes de una extensión superior, en tapa dura, notablemente ilustrados e impresos en papel de alto gramaje. Textos breves de Luísa Ducla Soares como O Homem das Barbas o O Senhor Pouca Sorte fueron publicados en único volumen con el título de Gente Gira (Livros Horizonte, 2002). De esta misma autora relatos como $O$ homem alto, a mulher baixinha y $A$ menina branca, o rapaz preto fueron agrupados en un mismo volumen con el título genérico de Tudo ao Contrário (Livros Horizonte, 2002). De esta misma colección destacamos $O$ Vizinho de Cima (1985), de António Torrado e ilustrado por Melo Frazão, por tratarse de un ejemplo innovador en el que el discurso verbal y el discurso pictórico forman un binomio eficaz y necesario. $O$ Vizinho de Cima es un texto narrativo en el que el mensaje que quiere transmitirnos su autor aparece implícito en la ilustración que figura en la portada del texto. De hecho, en este, como en otros títulos destinados a los lectores más pequeños, sólo la atenta observación de las imágenes ayuda a un entendimiento completo del sentido del texto y de las palabras que remiten frecuentemente a los elementos pictóricos. Es lo que constatamos, por ejemplo, en la secuencia lingüística con la que acaba $O$ Vizinho de Cima, una conclusión que exige, para la correcta comprensión de la resolución del conflicto, la mirada atenta de la ilustración que aparece junto al texto ya que el mensaje escrito solo menciona que "um dia, os dois amigos combinaram uma coisa, que experimentaram logo em seguida. E nunca mais houve arrelias. / São dois grandes inventores estes dois amigos vizinhos. E são amigos, o que também conta muito. / Se não fossem amigos esta história acabava mal. Assim acaba bem." (Torrado, 1985, s/p). De este modo el narrador de $O$ Vizinho de Cima, una voz plena de vivacidad, echa mano intencionadamente de un tipo de lectura en el que para llamar la atención del pequeño lector reclama en todo momento su acción sobre el mensaje de la obra. Por otro lado, las informaciones que sobre los personajes de esta obra aparecen son cada vez más pormenorizadas y van de lo más general a lo más concreto facilitando así su comprensión para el público infantil: «Neste prédio, vive um senhor com umas grandes barbas. / Pois é. Num dos andares deste prédio, vive um senhor com umas enormes barbas. / Pois é assim. No terceiro andar deste prédio de três andares, vive um senhor com umas enormíssimas barbas» (Torrado, 1985, s/p). Este cuento en formato de álbum narrativo representa un excelente ejemplo tanto de las capacidades narrativas de António Torrado como de las posibilidades de construcción de un tipo de texto en el que el componente lingüístico y verbal suscita la interpretación de un mensaje que debe interpretarse a la luz de las ilustraciones que adornan el texto.

De la editoral Livros Horizonte tenemos también que refererirnos a textos narrativos visuales como $O$ Gatinho Golias, $O$ Esquilo Estouvado, O Urso Pimpão y $O$ Burro Barnabé, cuatro títulos que componen la colección Histórias por Imagens con ilustraciones de autores variados y todos ellos extranjeros. Cabe señalar que en los últimos años de la década de los 70 del siglo $\mathrm{XX}$, este género 
editorial de la narrativa visual era escasísimo en Portugal. Además, en la actualidad no son abundantes los libros pensados para prelectores que se sitúan en este dominio de la narrativa visual como señalamos ya en otro trabajo (Silva, 2013).

Otro de los autores e ilustradores que escribe para un público prelector en los años 80 es Maria Keil. En la colección Histórias de Amor de Mais de Livros Horizonte ofrece un conjunto de títulos muy indicados para la formación de primeros lectores competentes. Destaquemos de esta colección As Três Maçãs, pequeño volumen narrativo en tapa blanda protagonizado por figuras infantiles anónimas cuyas intervenciones verbales aparecen insertadas directamente en bocadillos de un modo muy similar a lo que observamos en los cómics. La acción, que presenta una estructura basada en el esquema dar y quitar, y el conflicto que se va desarrollando (¿cómo dividir tres manzanas entre seis niños?) son elementos textuales comprendidos por el pequeño lector a partir de la observación de la acción de los personajes y del lenguaje que estos emplean. Si observamos las figuras de este texto y sobre todo las páginas que cierran el libro - un conjunto de piezas desorganizadas que invitan al juego del recorte de «cabeças, pernas, braços, enfim todas as diferentes partes do corpo» - parece claro que el destinatario de este texto verbal e icónico escrito por Maria Keil es un niño pequeño, en edad escolar, que se inicia en el mundo de los libros y la lectura de estos. Otro aspecto relevante de As Três Maçãs es la presencia de un texto en el que subyacen valores y principios humanos que un niño debe aprender: la amistad, la generosidad, el repartir lo que uno tiene, el dar y recibir, y el tener. Álbum narrativo innovador y envolvente, As Três Maçãs es un texto motivador para la formación del gusto literario en niños que han de ser lectores competentes.

Esta misma editorial y década, Livros Horizonte lanza la extensa colección Pássaro Livre con más de sesenta títulos para lectores medianos y autónomos de poesía y narrativa con textos e ilustraciones de autoría diversa. Sidónio Muralha, Fernando Miguel Bernardes, José Barata Moura, Luísa Ducla Soares, Maria Cecília Correia, Leonel Neves, Carlos Pinhão, Álvaro Magalhães, Matilde Rosa Araújo o José Jorge Letria son algunos de los autores que publican en Livros Horizonte y que constituyen la nómina de los escritores más significativos de la historia de la literatura portuguesa para niños ya que plasman las principales tendencias literarias y líneas ideotemáticas de la época histórico-cultural de la que nos ocupamos en este trabajo. Así, aparecen en sus páginas temas hasta el momento prohibidos en la literatura infantil anterior a los 80 como la crítica social (sobre todo en algunos títulos de Sidónio Muralha), la discriminación racial, la diferencias que existen entre las personas que son tratadas sin los falsos paternalismos de antaño, la 
preservación del medioambiente ${ }^{3}$, los conflictos familiares, el divorcio, la reinvención de algunos modelos tradicionales y el humor sarcástico. Todas estas temáticas ganan terreno en la nueva narrativa para niños del momento.

António Torrado y Maria Alberta Menéres ${ }^{4}$ son autores que, sobre todo en el caso del primer autor citado, publican varios cuentos y breves narraciones tomados de la literatura tradicional oral como, por ejemplo, los que fueron compilados en Histórias Tradicionais Portuguesas Contadas de Novo (2002) y los que se dedicaron a escribir (a veces, en coautoría) en forma de breves textos narrativos con un fuete componente cómico que queda plasmado en el tipo lenguaje utilizado así como las diferentes situaciones que pueden leerse en sus textos. De António Torrado, autor de una de las más extensas, sólidas y reconocida obras literaria para el público infantil, destacamos un título como el de O Elefante Não Entra na Jogada (1985). Y de Maria Alberta Menéres cabe señalar O Ouriço Espreitou Três Vezes (1981), un conjunto de tres historias aparentemente no relacionadas entre sí.

En este mismo campo de la narrativa humorística para niños, en ciertos casos de origen anglosajón y con el uso de los recursos de la ironía y la paradoja, cabe también destacar narraciones breves de Manuel António Pina ${ }^{5}$ publicadas en Gigões \& Anantes (1974) y O Têpluquê (1976), obras cuya singularidad lúdica tendría continuidad en títulos de este mismo autor, como por ejemplo Histórias que me Contaste Tu (1999), o en la obra de otros escritores para niños como Álvaro Magalhães e Isto É que Foi Ser (1983), O Menino Chamado Menino (1987) e Histórias Pequenas de Bichos Pequenos (1985).

Una nueva infancia, que es protagonista en diversos espacios de ficción y de formación como la escuela y la familia, aparece en títulos de diferentes autores como António Mota y O Rapaz de Louredo (1985), Pardinhas (1988) y Pedro Alecrim (1989). En estos textos, aparece un niño protagonista en edad escolar cuyo crecimiento es paralelo al del joven lector que puede perfectamente identificase con este protagonista.

Otros motivos que son objeto de ficción son la diversidad de personas y caracteres y el tema de la identidad y la alteridad personal. Así, podemos hablar de una nómina de autores que en sus obras para el público infantil se ocuparon de estos tópicos. Por ejemplo, O Passarinho de Maio (1990), de Matilde Rosa Araújo, es un texto en el que su protagonista, un pajarito, se enfrenta a un mundo en el que reivindica su libertad personal. Nacido de un huevo bajo la apariencia de un pollito

\footnotetext{
${ }^{3}$ A este título, vuélvase a ver, por ejemplo, Valéria e a Vida (1976), de Sidónio Muralha, y O Grande Continente Azul (1982) y Uma Viagem no Verde (1985), ambos de José Jorge Letria.

${ }^{4}$ Sobre esta autora véase GOMES, J. A y VASCONCELOS, Ana (2010): Maria Alberta Menéres Espreitou Três Vezes? Porto, Asa.

${ }^{5}$ Silva y Ribeiro, 2013.
} 
rojo y por tanto diferente al resto de animales de esta especie, esta figura animal sensiblemente humanizada se mueve en el seno de la naturaleza, espacio de autodescubrimiento, de crecimiento y de fortalecimiento. Su persistencia, su bondad de superar el miedo o sus limitaciones, su fuerza interior y su alegría de vivir contagian a todos los que lo rodea acabando por tener un efecto sorprendente y revitalizante sobre estos. No es casualidad que, justo a su lado, nazca un arbusto especial, un "cerejim" repleto de "bayas rojas y brillantes". Con temática similar, podemos citar O Dinossauro (1990), de Manuela Bacelar, y Os Ovos Misteriosos (1994), de Luísa Ducla Soares ${ }^{6}$, ambos situados en el género editorial del álbum narrativo para las primeras edades.

Otro título que se ocupa de la identidad personal es Uma Questão de Cor (1995), de Ana Saldanha. Su autora, una de las más conocidas en el universo de la escritura portuguesa para jóvenes que van dejando de ser niños, revela un conocimiento profundo del universo social y psicológico en el que se mueven los adolescentes de nuestros días. En esta obra, conocemos a Nina o Catarina, personaje y narradora hábil de una historia del día a día, de su propio día a día que, con una capacidad discursiva fuera de lo normal, nos hace entrar en su vida familiar y escolar. El relato, muy fluido, con dosis de información progresiva que mantiene al lector en vilo, se construye a partir de un registro coloquial y próximo al receptor que participa de las vivencias de Nina, una niña de trece años enfrentada a diversas problemáticas: el ataque cardíaco que sufre su abuela Olga, una profesora de portugués que cuando se enfada castiga a la protagonista con redacciones de 200 palabras y, sobre todo, tener que ceder su habitación a su primo Daniel que se incorpora a su escuela en la que tendrá que hacer frente a diversas situaciones de racismo. A partir de la figura de Daniel, a quien los compañeros de escuela se dirigen a él peyorativamente como "tostadinho" o "escurinho", Ana Saldanha textualiza el tema de la discriminación racial a partir de informaciones sobre comportamientos sociales tipificados y reprobables de los africanos en el Portugal de la época.

Problemáticas como esta de "substância realista" (Gomes, 1997, 49) pueden encontrarse también en obras como Diário de Sofia \& $C^{a}$ aos 15 anos (1994), de Luísa Ducla Soares; A Lua de Joana (1994), de Maria Teresa Maia Gonzalez, y en muchos otros títulos de una extensa colección escrita por Alice Vieira y editada por Editorial Caminho. De hecho, la narrativa infantil portuguesa destinada a lectores medianos y autónomos gana una nueva voz, la de la referida Alice Vieira ${ }^{7}$ que, en 1979, publica su primer texto narrativo, Rosa, Minha Irmã Rosa, al que hasta hoy han seguido otros veinte más, algunos de ellos verdaderos clásicos contemporáneos de la literatura portuguesa infantil y juvenil como, por ejemplo, Os Olhos de Ana

\footnotetext{
${ }^{6}$ Silva y Ribeiro, 2012.

${ }^{7}$ VVAA, 2010.
} 
Marta (1990). Se trata de un tipo de narrativa realista, intensa y envolvente, relatos de crecimiento, con problemáticas hábilmente urdidas, con personajes de personalidad fuerte y verosímil, historias que remiten en ocasiones a un pasado y cuyas temáticas de desasosiego personal (dilemas familiares, pérdida y muerte de seres queridos, niños huérfanos) invitan al lector a iniciar un proceso de reflexión sobre el sentido de su vivir. En Os Olhos de Ana Marta, los hilos de la afectividad, de la infancia y de la adolescencia, de las tensiones familiares, de los conflictos propios o ajenos y hasta de la imaginación nacida del contacto con muchos textos rescatados de la literatura oral, se van entrelazando en una textura discursiva original y ficcional. Es a través de una voz y de una sentimentalidad infantil que la narración acaba por enredar al destinatario extratextual en un universo misterioso, desvelado con mucha emoción y algunos toques de humor; un universo que es, a fin de cuentas, el de las distintas formas de actuar frente a la muerte, el cómo afrontar el sufrimiento causado por el dolor de la pérdida de un ser querido, el de niños y adultos que se relacionan en este contexto vivencial y el amor que surge entre las personas. El pasado y el presente parecen estar constantemente jugando al escondite en este texto, una estrategia que además también observamos en la caracterización de los personajes. Si con Marta, la protagonista, conviven otras figuras físicamente presentes en el texto, como Leonor, la vieja criada contadora de historias; Flávia, la madre ya sin edad de ser madre de nadie; y Lumena, también caminan a su lado otros personajes ausentes en la narración cuya existencia es, ante todo, imaginada por la niña de once años. La figura ausente físicamente, pero que al final es el eje a partir del cual todo el conflicto la historia se desarrolla, es Ana Marta, la hermana de la narradora, una niña cuya muerte representa el desasosiego general que sufre toda la familia, especialmente Marta, la protagonista del relato, que se debate en el desafío laberíntico no solo de conquistar el corazón de su madre Flávia, sino también autoconfirmarse como persona única e incapaz de sustituir a la hermana desaparecida. A partir de un discurso narrativo narración hábil, Os Olhos de Ana Marta es un texto envolvente, que cautiva sin dificultad la atención del lector sea joven o adulto. Su discurso poderosísimo da paso a un cautivante monólogo interior, casi siempre en un tono coloquial y muy próximo al destinatario juvenil.

También destinados a lectores medianos y autónomos, y teniendo como origen las narraciones de misterio y aventura al estilo de un autor inglés como E. Blyton, los títulos de la colección Uma Aventura, publicados por Editorial Caminho, de Ana Maria Magalhães e Isabel Alçada, fueron editados a partir de principios de los años 80 prosiguiendo su publicación hasta nuestros días. Su publicación representa un hito editorial incomparable y "verdadeiramente explosivo" (Gomes, 1991, 21). La misma editorial, y con la autoría de Magalhães y Alçada, lanza también en la misma época de los 80 otra colección, Viagens no Tempo, con propósitos pedagógicos y de formación histórico-cultural compuesta por narrativas cuya 
acción se sitúa en el pasado histórico que el niño lector puede conocer a partir de las diversas aventuras que viven los protagonistas de estos textos.

Otras editoras, como Ediciones Asa, buscando seguir la misma fórmula, publican nuevas colecciones como Triângulo Jota. Esta colección fue inaugurada con el título O Olhar do Dragão, de Álvaro Magalhães, cuyo éxito editorial favoreció la creación de una serie narrativa basada en este texto.

\section{CONCLUSIONES}

El presente estudio, con un objetivo muy claro que no es otro que el de la caracterización de la narrativa para el público infantil publicada en las dos décadas posteriores a la finalización de los regímenes dictatoriales en España y en Portugal (es decir, a partir de la segunda mitad de la década de los 70 del siglo XX) y la presentación de algunos títulos significativos de autores que empezaban a publicar lo que conocemos como cuento de autor, cuento en formato de álbum narrativo y novela infantil y juvenil, es una contribución a las historias de la literatura infantil españolas (Bravo-Villasante, 1995) y portuguesas (Gomes, 1997; Rocha, 2001) que, hasta la fecha, se han publicado y se han ocupado de esta cuestión. Así, el recorrido historiográfico que presentamos nos permite afirmar que, en los años 80 y 90 del siglo XX, en España y en Portugal, asistimos a una década de cambios que tienen que ver con un nuevo impulso creativo cuyo reflejo son un conjunto de textos en los que predomina la acción narrativa, el ludismo, la creatividad, la expresión autónoma y espontánea, el autodesarrollo de los personajes y la relación afectiva y emocional entre estos y el lector del texto. Todo ello es el resultado de un uso de la libertad de expresión coartada durante largos años. Del mismo modo los intereses de las editoriales, "autorizadas" a publicar a su medida y gusto, echan mano de traducciones de obras extranjeras que presentan realidades vitales distantes del mercado editorial español y portugués que debía seguir una línea editorial controlada por el régimen político de cada país.

Paralelamente, el creciente interés por la educación y formación intelectual de las jóvenes generaciones, con la implementación de estrategias pedagógicas diferenciadas que dedican una mayor atención a la lectura y a los lectores infantiles, suscita que, tanto en España como en Portugal, surga en pocos años un grupo relevante de autores y de ilustradores para los lectores referidos, además de un nuevo mercado editorial cuyo público es la población infantil. El libro infantil es concebido como una obra estéticamente apreciable, un objeto de referencia en la que puede descubrir nuevas realidades hasta el momento de difícil acceso debido a las políticas editoriales de los regímenes dictatoriales español y portugués.

Tal vez importe destacar que, en el caso portugués, el único manual escolar publicado por el Ministerio de Educación que, como no podía ser de otro modo, controlaba los saberes que la población joven debía adquirir, a partir de abril de 1974 pasa a ser editado por diferentes editoriales que publican variados manuales 
de lengua portuguesa en los que incluyen textos literarios de autores diversos. Se ofrece, de este modo, al lector infantil una diversidad de registros estéticos.

La proliferación, en sentido positivo, de nuevas editoriales (algunas de ellas en plena actividad editorial en la actualidad) y colecciones de libros, así como de nuevos autores e ilustradores como los mencionamos en este trabajo, se materializa en la publicación de obras con discursos literarios y grafismos originales. Las obras de ficción con nuevas temáticas es, sin duda, una señal de innovación en el universo editorial y literario al que nos estamos refiriendo. Véase, por ejemplo, el conjunto de títulos que se centran en temas como las penurias que pasan algunos personajes en su infancia, los movimientos migratorios y el multiculturalismo. En efecto, ficcionalizando diferentes temáticas, la nueva narrativa infantil presenta situaciones cuyo desenlace acaba siendo positivo debido a la restauración del equilibrio emocional de los personajes con los cuales el lector se siente plenamente identificado y es cómplice de sus vivencias y actuaciones. Por otra parte, la reinvención de lo maravilloso y de lo fantástico aparece a su vez junto a tramas de misterio y de búsqueda en las que no falta el componente cómico y humorístico.

A todo ello debemos añadir la aparición de nuevas publicaciones en el que el componente visual tiene tanta importancia como el componente narrativo. Estas publicaciones siguen la estela editorial anglosajona y francesa de los años 80 en los que los álbums narrativos (picture story books) y otro tipo de libros para el público infantil empiezan a ser editados en materiales tan diversos como, por ejemplo, la tapa dura y otros materiales esponjosos y moldeables.

Para concluir, en las décadas de los 80 y 90 del siglo XX, tanto en Portugal como en España, la literatura, y, en particular, la narrativa para los más jóvenes, aumentó tanto en diversidad como en cantidad y calidad de títulos que iban publicándose a un ritmo veloz. Se observa, así, una consolidación de un tipo de literatura infantil que, en última instancia, representó una respuesta afirmativa a las solicitudes de un grupo de lectores interesados en ser críticos con la realidad que les rodeaba y que apostaban por el descubrimiento de un nuevo mundo que hasta el momento les había sido vetado. La literatura narrativa infantil española y portuguesa de esta época es, sin duda, una de las principales puertas que abrieron las generaciones que, en los años 80 y 90 , buscaban participar en una sociedad abierta al cambio y que apostó fuertemente por la formación lectora de una población infantil que hizo decrecer las elevadas tasas de analfabetismo presentes en estos dos países entre los años 40 y 70.

\section{BIBLIOGRAFÍA}

ALBANELL, J. (1990): "Realástico fantismo", en Corrientes actuales de la narrativa infantil y juvenil española en lengua castellana, CUBELLS, F. (Coord.), Madrid, Asociación Española de Amigos del Libro Infantil y Juvenil, 25-29. 
BRAVO-VILLASANTE, C. (1985): Historia de la literatura infantil española, Madrid, Editorial Escuela Española S.A.

COLOMER, T. (1991): "Últimos años de la literatura infantil y juvenil", en Cuadernos de Literatura Infantil y Juvenil, 26, 14-24.

COLOMER, T. (1992): "Literatura infantil y juvenil en España (1939-1990), en Literatura infantil y juvenil. La infancia y sus libros en la civilización tecnológica, NOBILE, A. (Coord.), Brescia, Editrice La Scuola, 138-167.

COLOMER, T. (1998): La formación del lector literario: narrativa infantil y juvenil actual, Madrid, Fundación Germán Sánchez Ruipérez.

GARCÍA PADRINO, J. (1992): Libros y literatura para niños en la España contemporánea, Madrid, Fundación Germán Sánchez Ruipérez.

GASOL, A. \& LISSÓN, A. (1989): "Realismo... ¿con apellido?”, en Cuadernos de Literatura Infantil y Juvenil, 4, 20-7.

GOMES, J. A. (1991): Literatura para Crianças e Jovens. Alguns Percursos, Lisboa, Caminho.

GOMES, J. A. (1997): Para uma História da Literatura Portuguesa para a Infância e a Juventude, Lisboa, Ministério da Cultura/Instituto Português do Livro e das Bibliotecas.

GOMES, J. A., RAMOS, A. M. e SILVA, S. R. (2009): "Da Ditadura à Revolução, um percurso através da Literatura infanto-juvenil portuguesa" en A Memória dos Livros: História e histórias, RAMOS, A. M., GOMES, J. A. e SILVA, S. R. (Coord.), Porto, Deriva, 22-54.

GÓMEZ DEL MANZANO, M. (1987): El protagonista niño en la literatura infantil del Siglo XX, Madrid, Narcea.

LAGE FERNÁNDEZ, J. J. (1996): "La figura del maestro en la literatura infantil", en Amigos del Libro, 34, 43-50.

MARTÍNEZ, A. (1990): "La denuncia social en la literatura infantil", en Corrientes actuales de la narrativa infantil y juvenil española en lengua castellana, CUBELLS; F. (Coord.), Madrid, Asociación Española de Amigos del Libro Infantil y Juvenil, 85-89.

ROCHA, N. (2001): Breve História da Literatura para Crianças em Portugal, Lisboa: Caminho.

ROIG RECHOU, B., SOTO LÓPEZ, I. e NEIRA RODRÍGUEZ, M. (2013): Premios Literarios e de Ilustración na LIX, Vigo/Santiago de Compostela, Xerais/LIJMI/CRPIH.

SILVA, S. R. da (2008): "O País das Pessoas de Pernas para o Ar. Um olhar sobre a literatura infantil das décadas de 60 e 70, com a imaginação a brincar às escondidas com a censura", en 1970 - Marcha Fúnebre, PAÇO, A. S. do (Coord.), Lisboa, Planeta De Agostini, 154-161.

SILVA, S. R. da (2011): “A presença dos álbuns narrativos na literatura portuguesa para a infância: primeiras manifestações", en Entre Textos. Perspectivas sobre a Literatura para a Infância e a Juventude, Porto, Tropelias \& Ca, 221-237. 
SILVA, S. R. y RIBEIRO, J. M. (2012): Luísa Ducla Soares: Uma Escrita Lúdica, Livre e Critica, Porto, Tropelias \& $\mathrm{C}^{\mathrm{a}}$.

SILVA, S. R. y RIBEIRO, J. M. (2013): Coisas que Não Há: sobre a escrita de Manuel António Pina, Porto, Tropelias \& Ca.

SILVA, S. R. da (2013): "Quando a ilustração conta a história: narrativas visuais para a infância e formação de leitores", en Actas do XII Congresso Internacional Galego-Português de Psicopedagogia, Braga, Universidade do Minho, 1353-1359.

SILVA, S. R. da (s/d): "Os Olhos de Ana Marta (comentário)" [en línea]. Disponible em Web: http:// www.casadaleitura.org [Consulta 24 de enero 2014).

STRAUSFELD, M. (1989): "El realismo crítico en la literatura infantil y juvenil", en Cuadernos de literatura infantil y juvenil, 4, 83-7.

VALRIU i LLINÀS, C. (1994): Història de la literatura infantil i juvenil catalana, Barcelona, Pirene educació.

VÁSQUEZ VARGAR, M. (2003): "La actual narrativa infantil y juvenil española", en Filología y Lingüística, 29, 61-84

VVAA (1950): Instruções sobre Literatura Infantil, Lisboa, Direcção dos Serviços de Censura.

VVAA (2010): Solta Palavra 16 (Boletín del Centro de Recursos y Investigación Sobre Literatura para la Infancia y Juventud), Porto, Centro de Recursos e Investigação sobre Literatura para a Infância e Juventude.

VIÑAO, A. (2009): "La alfabetización en España: un proceso cambiante de un mundo Multiforme", en E-fora, 39, 5-19.

WENSELL, U. (2000): "El papel de las ilustraciones en los libros para niños", en Presente y futuro de la Literatura Infantil, Cuenca, Ediciones de la Universidad de Castilla-La Mancha, 151-156. 